\title{
Necessidades Nutricionais de Vacas Leiteiras: criação de aplicativo para cálculos
}

\section{Nutritional Needs of Dairy Cows: creation of an application for calculations}

\author{
Adriano Medeiros Alves da Silva ${ }^{(1)}$; José Crisólogo de Sales Silva ${ }^{(2)}$
}

(1) ORCID 0000-0002-3771-562X. Técnico em Agropecuária do Banco do Nordeste do Brasil (BNB); Especialista em Produção Animal e Desenvolvimento Rural pela Universidade Estadual de Alagoas (UNEAL). E-mail: medeiros-adriano@ hotmail.com; http://lattes.cnpq.br/7730274142032080.

(2) ORCID: http://orcid.org/0000-0001-8687-0952, Universidade Estadual de Alagoas, Uneal, Professor Titular, Grupo Caatinga de Pesquisa, BRAZIL, Email: jose.crisologo@uneal.edu.br

RESUMO: O sistema NRC determina as necessidades nutricionais dos animais a partir de cálculos padronizados de acordo com a finalidade da criação e outros dados dos animais. No entanto, nem todos os criadores e muitos técnicos têm dificuldade em utilizar corretamente tal padrão. Este trabalho de conclusão de curso foi desenvolvido com o objetivo de fundamentar e executar a elaboração de um aplicativo para android que tenha como principal funcionalidade o cálculo das necessidades nutricionais para vacas leiteiras. Metodologicamente o trabalho se desenvolveu por meio de pesquisas bibliográficas para determinar os critérios a serem utilizados nos cálculos das necessidades alimentares dos animais escolhidos para o estudo. Em seguida, fundamentada a escolha do NRC como base para tais cálculos, desenvolveu-se o aplicativo que pode ser instalado e executado em aparelhos que possuam sistema android e a partir do fornecimento dos dados dos animais a serem alimentados, o aplicativo apresenta como resultado as necessidades nutricionais. A possibilidade de o criador ter à mão um sistema que facilita a alimentação de seu rebanho contribui para uma maior lucratividade e qualidade da criação.

Palavras-chave: Nutrição; Cálculo de Ração; Produção.

ABSTRACT The NRC system determines the nutritional needs of animals based on standardized calculations according to the purpose of rearing and other animal data. However, not all breeders and many technicians have difficulty using this pattern 
correctly. This course conclusion work was developed with the objective of founding and executing the elaboration of an application for android that has as main functionality the calculation of the nutritional needs for dairy cows. Methodologically, the work was developed through bibliographic research to determine the criteria to be used in calculating the dietary needs of the animals chosen for the study. Then, based on the choice of the NRC as the basis for such calculations, an application was developed that can be installed and run on devices that have an android system and from the provision of data on the animals to be fed, the application presents as a result the nutritional needs. The possibility for the breeder to have a system at hand that facilitates the feeding of his flock contributes to greater profitability and quality of the breeding.

Keywords: Nutrition; Feed Calculation; Production

\section{INTRODUÇÃO}

A importância do leite está contextualizada tanto no âmbito produtivo quanto da economia mundial nos países considerados em desenvolvimento, tendo aumentado a produção em mais de 50\% nos últimos 30 anos, segundo dados da Food and Agriculture Organization of the United Nations - FAO (FAO, 2019).

O Brasil é o quinto país em produção de leite. No Brasil, o leite é um dos seis produtos mais importantes da agropecuária brasileira, sendo essencial no suprimento de alimentos e na geração de emprego e renda para a população (EMBRAPA, 2019).

A produção leiteira brasileira é considerada muito importante para a agropecuária, pois consiste em uma atividade praticada por 1,3 milhões de produtores rurais do País. De acordo com Costa (2015), a sua importância também se deve ao fato de empregar no setor mais pessoas que a indústria e a construção civil.

Mesmo com o aumento da produção de leite no Brasil, ainda se considera que o aumento não é significativo, visto que a média brasileira ainda é inferior a países vizinhos como aos índices da Argentina. Isso deve a fatores como falta de especialização, alimentação inadequada do rebanho, manejo incorreto, entre outros fatores (LOPES, 2017).

Porém, é necessário que o setor da bovinocultura brasileira se torne mais competitivo tanto em relação à qualidade de seus produtos, como em eficiência e produtividade. Tudo isso passa pela questão nutricional do rebanho. Já que o principal custo nas criações de vacas leiteiras é o da alimentação e dessa base nutricional resultará 
o rendimento financeiro da atividade, tendo em vista que a produção dependerá do atendimento ideal das necessidades nutricionais dos animais.

Aplicativo para smartphone e tablet vem sendo a cada dia uma ferramenta para o homem do campo, tornando-se cada vez mais comum na atividade de bovinocultura de leite, em virtude da complexidade da cadeia produtiva, e pela necessidade de manter a sustentabilidade da mesma (DAL'AGNOL, 2016).

A importância do desenvolvimento deste aplicativo se dá pelo fato de que, apesar de o NRC ser uma referência amplamente divulgada e reconhecida como válida para os cálculos de necessidades nutricionais do gado leiteiro, muitos criadores e técnicos da área não sabem aplicar o conhecimento corretamente.

Assim este trabalho de conclusão de curso foi desenvolvido com o objetivo de fundamentar e executar a elaboração de um aplicativo para android que tenha como principal funcionalidade o cálculo das necessidades nutricionais para vacas leiteiras

\section{MATERIAIS E MÉTODOS}

Para realização dos cálculos de exigência nutricionais, são comumente utilizadas diversas tabelas como as do National Research Council - NRC, publicações de NRC (1989 e 2001), Agricultural and Food Research Council - AFRC, publicação AFRC (1993), Institut National de la Recherche Agronomique - INRA, publicações Jarrige (1988) e INRA (2007) ou mesmo o Commonwealth Scientific and Industrial Research Organisation - CSIRO, com publicação CSIRO (2007), todas estrangeiras, desenvolvidas, respectivamente, nos Estados Unidos, na Grã-Bretanha, na França ou na Austrália (GONÇALVES et. al., 2009). Para este trabalho escolhemos utilizar as equações propostas pelo NRC 2001.

Por meio de estudo do NRC 2001, observou-se que várias são as exigências nutricionais das matrizes bovinas lactantes, desta forma, selecionaram-se para estimativa os seguintes itens com suas respectivas fórmulas:

1. Consumo de matéria seca (CMS);

$\mathrm{CMS}=[(0,372 \times \mathrm{LCG})+(0,0968 \times \mathrm{XM})] \times\left(1-2,7183^{(-(0,192 \times(\text { semana lactação+3,67) }))}\right.$ )

LCG (Leite corrigido pela gordura) $=$ (gordura corrigida $\mathrm{x}$ leite produzido $)+(15 \times$ (leite produzido $\mathrm{x}$ gordura do leite)

PM $($ peso metabólico $)=$ Peso vivo ${ }^{0,75}$ 
